\title{
¿Novohispanos sinistrorsos? Apuntes bibliográficos sobre el estudio del hebreo en la América Latina de la Edad Moderna
}

\author{
Jesús de Prado Plumed ${ }^{1}$
}

Recibido: 8 de noviembre de 2018 / Aceptado: 28 de marzo de 2019

Resumen. La historia del estudio y el cultivo del hebreo en la América Latina de la Edad Moderna suponen un terreno prácticamente desconocido. A partir de indicios bibliográficos, tanto de impresos como de manuscritos, tanto del uso como del comercio librario en esa época y geografía, pretendemos ofrecer un primer acercamiento sistemático, sin pretender ser exhaustivo, a este ámbito de estudio que, con base en las fuentes disponibles, muchas inéditas, presenta interesantes perspectivas de investigación. Palabras clave: Hebraísmo cristiano; historia intelectual de la América colonial; humanismo bíblico; Martín del Castillo; Edad Moderna.

[en] Sinistrorse New-Spaniards? Bibliographical Notes on the Study of Hebrew in Early Modern Latin America

Abstract. The history of the study and cultivation of the Hebrew language in Early Modern Latin America remains practically unknown terrain. This article proposes a first-hand and systematic -albeit not comprehensive- contact with this area of research, through the study of bibliographical evidence found in the documents available - printed works and manuscripts regarding both the use and commerce of books in that time and space- many of which are unpublished. This area of research presents interesting research perspectives.

Keywords: Christian hebraism; Intellectual history of colonial Latin America; Biblical humanism; Martín del Castillo; Modern age.

Sumario. 1. Introducción. 2. Caracterización del hebraísmo cristiano. 3. Un biblista políglota novohispano. 4. Cábala y lectura hebraística en la Nueva España. 5. Exégesis, filología bíblica y "judíos nuevos". 6. Conclusiones y perspectivas de investigación. 7. Referencias bibliográficas.

Cómo citar: Prado Plumed, J. de (2019) “¿Novohispanos sinistrorsos? Apuntes bibliográficos sobre el estudio del hebreo en la América Latina colonial", en Revista Complutense de Historia de América $45,69-88$.

1 Colegio de Historia, Facultad de Filosofía y Letras y Posgrado en Historia, UNAM.

E-mail: jesusdeprado@comunidad.unam.mx

Agradezco a Viviana Avendaño Martínez su colaboración en la revisión final de este artículo. 
Para Miriam y Mateo, novohispanos hebraispanos

\section{Introducción}

Quien sin prevención lee por primera vez las dos ediciones del primer vocabulario "de la lengua mexicana" (es decir, el náhuatl) "y castellana" de Alonso de Molina (ca. 1513-ca. 1585), tanto en su edición de 1555 como en la de $1571^{2}$, se encuentra con varios registros que en un primer momento resultan curiosos: ¿cuál es la razón para que el vocabulario de Molina, guiado por lo que parecen las preocupaciones prioritarias de los primeros colonizadores y evangelizadores en lo que respecta a la comunicación con los indígenas, incluya lemas como "iudería | ayuntamiento de judios, judiome ynnecentlaliliz", "iudio. judio tlacatl. judio oquichtli / iudia. judio ciuatl. / iudio retajado ${ }^{3}$. tlaxipintectli judio. / iudiega cosa. judioyotl. Judiocayotl"? ${ }^{4}$ ¿Cuál era en efecto la necesidad de precisar el campo semántico del judaísmo en los actos comunicativos de los recién llegados? ${ }^{5} \mathrm{El}$ consenso teológico del mundo cristiano, tanto católico como protestante, imponía la prevención frente a lo judío, a pesar de que después de las expulsiones y conversiones forzosas de 1492, 1496 y 1498 no hubiera presencia legal del judaísmo en la península Ibérica y que, para las primeras décadas del siglo XVI, el judaísmo tuviera escasa representación en la Europa occidental ${ }^{6}$. Lo judio no dejó de ser un elemento integrante de las preocupaciones de la época en el ámbito hispánico, transplantado y reinterpretado en la Nueva España, donde igual se mencionará a los "judíos ingleses" (xotiome ingleses) que conquistaron Veracruz, haciendo de "judío" (jotiyo, xotiotin en el préstamo adaptado en el náhuatl) el sinónimo por excelencia de "hereje, descreído" para el cronista nahua ${ }^{7}$, o como sinónimo igualmente del idólatra que en una ritualización indígena de los mitos cristianos persigue al Sol/Jesucristo en la representación pascual de la Judea de los cora (na'ayarij) del estado de Nayarit ${ }^{8}$.

Íntimamente unido a lo judío desde la antigüedad se encuentra lo hebreo y, en particular, la lengua hebrea, cuyo cultivo y estudio no ha cesado desde los primeros tiempos de la Iglesia cristiana, tanto la de lengua latina como la de lengua griega. Aunque con frecuencia se han hecho sinónimos, judio y hebreo no lo son en sentido estricto. Por hebraísmo entendemos una disciplina dentro de las prácticas eruditas

2 Es decir, Molina, 1555: II; Molina, 1571,_respectivamente. Las signaturas topográficas de estas ediciones en el Fondo Reservado (en adelante: RFO) de la Biblioteca Nacional de México (BNM) son respectivamente RSM 1555 M4MOL (tres ejemplares) y RSM 1571 M4MOL (cuatro ejemplares), al parecer conservados en la llamada Sala Mexicana de la BNM. No he consultado directamente ninguno de esos ejemplares sino solo reproducciones.

3 Es decir, "circunciso". Era por supuesto esta marca corporal el índice fundamental de genealogía judía o de práctica judaizante tras la prohibición de la práctica del judaísmo en los territorios de la Monarquía católica. Retajar es la forma que los propios judíos de habla judeo-española utilizaron después de 1492: Romero Castelló, 1998.

4 Molina, 1555: f. 144r-v; Molina, 1571: f. 73r (K71r).

5 Especialmente en el entorno de la evangelización en el que, de manera muy clara, se inserta la obra de Alonso de Molina. La bibliografía, mexicana y foránea, sobre el tema es casi inabarcable y excede la competencia de quien esto escribe. Un trabajo reciente, que parece recoger las aportaciones anteriores y entablar diálogo con ellas, es Murillo Gallegos, 2012.

6 Ruderman, 2010.

7 Zapata y Mendoza, 1995: 600-601, referencia obtenida en Wood - Sullivan, 2007.

8 Neurath, 2004: 118-119; González Laporte, 2000-2001. 
de la Edad Moderna que, desde y para el mundo cristiano, se interesa por los textos de los distintos cánones judíos: Biblia hebrea, textos en griego de autores judíos, Talmud, filosofía de autores judíos disponible en hebreo, exégesis bíblica, etc., con ambiciones fundamentalmente cristológicas. El hebraísmo se constituye, pues, como una práctica intelectual y cultural llevada a cabo fundamentalmente por autores cristianos para lectores cristianos?

A menudo se ha hablado de un "antijudaísmo sin judíos" como descripción de este mismo consenso teológico que para justificar la segunda alianza (de Cristo) tenía que negar la primera (la de Dios con el pueblo judío). Pero ese antijudaísmo sin judíos, como paradigma teológico, intelectual, cultural, social y hasta político, fue acompañado de un hebraísmo también sin judíos. Conviene precisar un dato que quizá pueda parecer paradójico en una primera lectura: el género discursivo del antijudaísmo y el hebraísmo son perfectamente compatibles ${ }^{10}$. De hecho, buena parte de los autores de polémica antijudía, uno de los géneros más representativos de la cultura de la disputa intelectual en el ámbito teológico de la Edad Moderna, son a su vez notorios practicantes del hebraísmo, con conocimientos que a menudo no pueden calificarse de discretos ${ }^{11}$. Dos ejemplos, entre muchos. En primer lugar, ubicamos los escritos tardíos de Martín Lutero, que derrochan un antijudaísmo que a veces bordea casi lo biológico (entrando pues casi en el antisemitismo contemporáneo) mientras que sus conocimientos de la lengua y la Biblia hebreas se han acreditado sobradamente como profundos y atentos ${ }^{12}$. $\mathrm{O}$, como segundo ejemplo, en el ámbito ibérico uno de los inquisidores más eficaces de la primera y cruenta época de la Inquisición portuguesa fue Jerónimo de Azambuja (latinizado como Hieronymus ab Oleastro), muerto en 1563, quien fue uno de los más preclaros hebraístas a la vez que uno de los más finos exegetas bíblicos del Quinientos ibérico ${ }^{13}$.

\section{Caracterización del hebraísmo cristiano}

El hebraísmo, en la época que va del siglo XV al siglo XVIII, era, por tanto, un esfuerzo de apropiación de lo que parecía aprovechable de esta tradición rabínica para la civilización cristiana ${ }^{14}$. El archierudito ibérico Benito Arias Montano (m. 1598), por poner un solo ejemplo notorio, hizo su comentario a los Evangelios a través de

9 Las excepciones son pocas pero importantísimas por la calidad e influencia de sus contribuciones, como las de Elías Levita (m. 1549) o Abraham de Balmes (m. 1523) ambos activos en ámbito italiano. Sobre el primero, véase todavía Weil, 1963; sobre el segundo, Campanini, 1997. Un tropo habitual del hebraísmo cristiano, que más adelante en este artículo veremos reflejado para la Nueva España, es el del "maestro", judío o converso de judío, que enseña al cristiano los arcanos de la sabiduría hebraica, radicándose así en un locus de autoridad. Sobre este tropo, véase Szpiech, 2013.

10 Oberman, 1992.

11 Weijers, 2013: 177-238.

12 Kremers - Siegele-Wenschkewitz - Klappert, 1985, en especial los capítulos obra de Joop Boendermaker y Stefan Schreiner.

13 La falta de comprensión de la absoluta falta de ambivalencia entre la ocupación inquisitorial y el estudio hebraísta es lo que llevó a Herman Prins Salomon e Isaac S.D. Sassoon, en el prefacio a su traducción inglesa de Saraiva, 2001: XIII, nota 10, a tildar la actitud de Azambuja de "esquizofrénica". Nos falta una monografía que aborde en profundidad los ambiciosos proyectos exegéticos del inquisidor y hebraísta portugués. Mientras tanto, sobre el personaje véase Coelho, 2001, que recoge la bibliografía anterior. Sobre su actividad inquisitorial, puesta en contexto, véase Marcocci - Paiva, 2013: 39 y 92.

14 Véase el elegante estado de la cuestión en Dunkelgrün, 2017. 
una lectura de las fuentes judías que le ayudaron a comprender el contexto material de la época y vida de Jesús de Nazaret ${ }^{15}$. Era, pues, una actividad realizada fundamentalmente por cristianos con destinatarios fundamental e igualmente cristianos.

Quienes se dedicaron al hebraísmo de forma profesional conformaban, por fuerza, un grupo reducido puesto que el conocimiento suficiente del hebreo o de la lengua hermana del hebreo en la tradición judía, el arameo, nunca fue (ni es, dicho sea de paso) un asunto de multitudes ${ }^{16}$. Para evaluar correctamente el grado de influencia que esta corriente intelectual tuvo en la confirmación del consenso erudito de la época hay que atender, por igual, al registro de autores tanto como al de lectores pero, también, a los lectores de hebreo como a los lectores de obras que, escritas en latín o en lenguas vernáculas, tuvieran como base necesaria el corpus hebraístico, tanto en hebreo como en otras lenguas, como el griego. Un ejemplo de esto último constituirían los innumerables lectores de Flavio Josefo durante toda la Edad Media y Moderna ${ }^{17}$. Así, para un avalúo de más amplio espectro, conviene la definición de lector hebraísta más que la de autor hebraísta o incluso hebreo. Para la historia cultural de esta práctica intelectual, la de la familiaridad con las obras que componen el corpus bíblico y parabíblico en sus lenguas originales, conviene más, a mi juicio, la perspectiva de la lectura que la perspectiva de la autoría. Autores habrá, necesariamente en actividad tan especializada, pocos; lectores (y alguna lectora), sin embargo, nunca faltarán si los consideramos teniendo en cuenta que las élites de formación universitaria y de formación teológica fueron siempre escasas en número pero muy influyentes en lo intelectual, lo cultural y lo político ${ }^{18}$.

Yendo específicamente a la Nueva España encontramos eruditos de ambos tipos: tanto autores de obra original en materia de hebraística, con conocimientos más que notables del hebreo y otras lenguas orientales, como avezados lectores que se aprovecharon de lo que los hebraístas profesionales iban publicando en las mismas fechas. En los siguientes epígrafes trataremos de ambos aspectos con tres ejemplos.

15 Arias Montano, 1575. No he encontrado por el momento ejemplares de esta obra en bibliotecas de fondo antiguo mexicanas. No es improbable que aparezca. Sobre ediciones de Amberes en bibliotecas novohispanas, véase Manrique Figueroa, 2009.

16 El primer profesor de hebreo de la pujante universidad humanista de Alcalá de Henares, el hebraísta converso Alfonso de Zamora (m. ca. 1545) nunca parece que tuvo más de siete alumnos. Un servidor, que estudió letras hebreas y arameas en la Universidad Complutense de Madrid sucesora directa de la alcalaína donde prestó sus servicios Zamora, nunca tuvo más de siete compañeros de clase en la misma disciplina. Con todo, análisis de cierto pesimismo respecto de la difusión del hebraísmo entre el público lector erudito de la Edad Moderna europea, y de la expansión colonial europea en las Américas y Asia, quizá deba revisarse para acomodar mejor lo que vamos sabiendo como prácticas de lectura o corrientes de pensamiento. Un análisis que disminuye la importancia de estas preocupaciones intelectuales está recogido en Rothschild, 1992. Creo que las conclusiones de Rothschild pueden, a su vez, reformularse de una forma más optimista, si no por lo que afecta al conocimiento efectivo del hebreo entre ese gran público letrado (algo ilusorio, a decir verdad, si hemos de juzgar su magnitud real), al menos por lo que puede constatarse del interés, más o menos profundo, por el hebreo y la sabiduría de Israel.

17 Grafton, 2014.

18 Grafton - Weinberg, 2011: 29. El protagonista del libro, Isaac Casaubon (m. 1614) es, por supuesto, uno de los principales helenistas de finales del siglo XVI y principios del XVII, de importancia pareja a la de su amigo epistolar y correligionario (ambos eran protestantes franceses) Joseph Juste Scaliger (José Justo Escalígero, en la forma hispanizada de su nombre). Falta por hacer un estudio monográfico de las mujeres que mostraron interés en las disciplinas hebraicas, como la hispano-portuguesa Luisa Sigea (m. 1560), la alemana Margaretha Sibylla von Einsiedel (m. 1690) o la germano-holandesa Anna Maria van Schurman (m. 1678), cuyas etopeyas en las fuentes que nos las describen parece responder más al modelo discursivo del Wunderkind que a una auténtica evaluación de su saber. Un estado de la cuestión puede hallarse en Robin, 2016. 
En primer lugar, el franciscano Martín del Castillo, quien se adscribe a la primera categoría de autor hebraísta. Fue sin duda uno de los más eximios polígrafos en tierras novohispanas del que sería muy necesario escribir su biografía intelectual, no solo para el campo de la filología bíblica, de la que el hebraísmo, en Occidente, no es más que una rama, sino por la correcta comprensión sino para aprehender los alcances de la erudición novohispana en el Setecientos. En segundo lugar, a través de una lista de libros enviada con destino en la Nueva España, examinaremos el rango de géneros y lecturas de que podían disponer los interesados en esta materia en la América Latina colonial, haciendo hincapié en el hecho de que sea el único registro de momento donde se haya identificado un libro de cábala cristiana en tierras americanas y en época virreinal. Finalmente, discutiré un ejemplo de lectura criptojudía con el caso paradigmático de Luis de Carvajal/José Lumbroso. Los criptojudíos, "judaizantes" en la categorización penal de los códigos inquisitoriales, fueron los grupos o individuos de origen judeoconverso (o no) que se sintieron compelidos a convertirse al judaísmo, lo que en la España y sus Indias en la Edad Moderna suponía, desde luego, la posible persecución inquisitorial y en última instancia la muerte ${ }^{19}$.

\section{Un biblista políglota novohispano}

En el segundo tercio del siglo XVII, el franciscano español radicado en México Martín del Castillo (1600-1680), religioso de la principal fundación franciscana de la Ciudad de México, autor de varias obras de exégesis bíblica que consiguieron el éxito relativo de ser reeditadas en la Europa no hispánica, redactó durante un largo periodo de más de dos décadas una gramática hebrea y una griega ${ }^{20}$. La gramática hebrea, que acabó recibiendo el ingenioso título de Arte hebraispano, fue finalmente publicada en Lyon (León de Francia, como reza su pie de imprenta) en la casa de Florian Anisson, afamado mercader de libros con tienda en Madrid ${ }^{21}$. Esta gramática tiene el mérito de haber sido, que sepamos, el primer arte hebreo de gramática cuya metalengua es el español. Parece que el mérito, relativo, de haber sido la primera escrita en suelo americano corresponde a un epítome gramatical hebraico redactado en el Brasil bajo dominación holandesa y, por tanto, con población judía legalmente

19 En la Edad Media y en la Moderna tenemos ejemplos de conversiones al judaísmo, como la del monje de la Italia normanda Johannes de Oppido (s. XII) o Lope de Vera y Alarcón (m. 1644), unánimemente reconocido como cristiano viejo, caso estudiado en Bodian, 2007: 153-177. Conviene siempre recordar que en el caso de los individuos o comunidades, como el círculo de los Carvajal o de las Ribera en el México virreinal o de Amsterdam a partir del siglo XVII, también estuvo compuesto por personas que imaginaron su genealogía judía, sin que pudiera siempre rastrearse con fiabilidad sus presuntos orígenes judíos. Además, en la misma familia podían convivir experiencias de fe y actitudes ante el judaísmo radicalmente opuesta, como supone el caso de Luis de Carvajal, "el Mozo", judaizante y dogmatista, y su tío, Luis de Carvajal y de la Cueva, "el Viejo", fiel católico hasta su muerte. Sobre este último, véase ahora en español Temkin, 2017: 201-211. Agradezco a Benny Temkin y Sylvia Podolsky que me consiguieran un ejemplar de tan importante libro.

20 Beristáin y Souza, 1883: 273-275. Sobre la gramática griega de Del Castillo en su contexto, véase Andrés Castellanos, 1988: 89-90 y 96-103. Una lista actualizada de algunos de sus escritos, manuscritos e impresos, incluyendo algunos aún no he podido localizar, en Reinhardt, 1990: 104-106. La lista no es exhaustiva.

21 La referencia es Castillo, 1676a. Ha tenido una amplia difusión, pudiendo encontrarse una abundancia de ejemplares tanto en colecciones públicas y privadas, dentro y fuera de México. Como curiosidad erudita, el padre Garibay Kintana dio noticia publicística de esta obra en varios artículos publicados en el diario mexicano El Universal: Garibay Kintana, 1955a, 1955b, 1955c. Quizá no esté de más señalar que donde Del Castillo yerra en su hebreo, yerra asimismo el padre Garibay. 
establecida. Este manuscrito brasileño, hoy conservado en Amsterdam, quedó en estado manuscrito y está redactado en hebreo. Sería, pues también, el primer manuscrito hebreo escrito en las Américas ${ }^{22}$. Sin embargo, la gramática de Del Castillo sería la primera sistemática y amplia redactada en este continente, casi un siglo antes de la gramática publicada por el judío convertido Judah Monis para la enseñanza del hebreo en Harvard ${ }^{23}$.

Concebido y redactado íntegramente en el Convento Grande de San Francisco de la capital novohispana, solo un investigador contemporáneo, que sepamos, ha puesto su atención en evaluar críticamente el tratado gramatical del franciscano Del Casti1lo. En esa brevísima revisión se expresa un juicio fundamentalmente negativo sobre la obra de Del Castillo que yo encuentro fundamentalmente injusto, y que ya había sido enunciado en el siglo XIX por otro estudioso español del hebraísmo ${ }^{24}$. En este sentido, la primera y aun la segunda generación novohispana que todavía se sirvió de la obra de Martín del Castillo fue quizá más justa en el juicio que le mereció el trabajo del franciscano burgalés radicado en la Nueva España. Por ejemplo, a finales ya del siglo XVIII y refiriéndose a su gramática griega ${ }^{25}$ que comparte características programáticas y público destinatario con el Arte hebraispano, Juan Luis Maneiro señalaba en su tratado biográfico de mexicanos notables publicado en 1792 que, "Y nosotros, ciertamente, entregamos mucho estudio a la gramática de Martín [del Castillo] y no la consideramos inferior a la [del Seminario] de Padua, o a alguna otra de las más recientes. [...] Entre los maestros tuvo el primer lugar Martín Castillo [sic, en la traducción] [...] quien de su propio ingenio compuso una gramática griega, y propagó entre los adolescentes de su época el muy útil estudio de las letras griegas"26.

De este franciscano burgalés radicado en la Nueva España quedó una cantidad apreciable de trabajos. En 1675, en la Ciudad de México, vio la luz un arte mnemotécnica bíblica, prontuario de pasajes veterotestamentarios útiles para la exégesis bíblica que tuvo una cierta difusión, su Ars biblica siue Herma memorialis ${ }^{27}$. Más de un siglo después, en 1778, una imprenta de la andaluza ciudad de Écija, entonces en el reino de Sevilla, aún vio la utilidad de volver a sacar a la circulación esta obra ${ }^{28}$. En esta reedición se explica el propósito de la obra:

Este Librito se reduce à una Arte Biblica, o Arte de memoria de la Biblia, reducida à versos Exametros, y tal vez Disticos, los quales forman las dicciones de la letta [sic, por letra] mas abultada, y su principio se denota con la * estrella, ò Asterisco. Cada palabra encierra por la mayor parte un Capitulo de la Sagrada Escritura, à la qual explica el rengloncito, que cada una tiene por cima en letra de menor tamaño. Los numeros vulgares 1.2.3.\&c. denotan el Capitulo, que comprehenden cada palabra ${ }^{29}$.

Offenberg, 2003.

Pfeiffer, 1955: 369-370.

24 García-Jalón de la Lama, 2004; García Blanco, 1846: 436. Quien subscribe está preparando en la actualidad un trabajo en que reviso el contenido propiamente gramatical del tratado de Del Castillo, puesto en el contexto del hebraísmo cristiano de su época.

25 Es decir, Castillo, 1678.

26 Tomo la referencia de Osorio Romerio, 1986: 79, de quien tomo asimismo la traducción de la cita original en latín.

27 Castillo, 1675.

28 Castillo, 1778

29 Ibídem, "Norma para la inteligencia de la Arte Biblica", f. [M8r]. 
Es esta Ars biblica una obra de no poco mérito que discute, por ejemplo, “¿Qué significa la Cábala entre los rabinos?" (Quid nomine Kabbâla apud Rabinos designetur?), dando a continuación una descripción minuciosa pero concisa y respetuosa de los beneficios que para el estudio bíblico en general, sin restricción para judíos o cristianos, tiene la Cábala, llegando a encontrar significados cabalísticos a algunos pasajes neotestamentarios ${ }^{30}$. Es, de momento, un ejemplo único de erudito en la Nueva España que se interese por la Cábala pero un ejemplo, nos atrevemos a sugerir, que sería extraño que fuera, aunque señero, aislado. Este interés de Martín del Castillo merece, qué duda cabe, un trabajo de investigación específico. El estatus de la Cábala entre los hebraístas cristianos hispánicos nunca pasó, al menos de palabra, de controvertido cuando menos ${ }^{31}$.

De fecha tan relativamente temprana para la cronología atestiguada de nuestro autor franciscano como 1637, se conserva en manuscrito, inédito, una disputatio escolástica. Para la fecha de la primera unidad textual y quizá codicológica de este manuscrito, las Conclusiones biblicae, fray Martín, que se identifica como "in Sacra Theologia iam proxime iubilandus" (¿faltaría lector, es decir, catedrático?) ${ }^{32}$, recurre al argumento de que el mejor arsenal de la polémica cristiana es recurrir al estudio de las lenguas clásicas de las tradiciones bíblicas, a saber, hebreo, arameo (Chaldaice seu Syriace) y griego pero el franciscano ya pasado por la Nueva España añade una cuarta lengua a estas: el náhuatl (y añadamos también el árabe) ${ }^{33}$. El náhuatl, para Martín de Castillo, forma sus pronombres personales igual que el hebreo, desarrolla la flexión verbal tanto para formas masculinas como femeninas y posee un afijo pronominal de primera persona del singular $n i$-, igual que el hebreo (aunque, en puridad, el del náhuatl sería un prefijo de sujeto y el del hebreo, un sufijo de objeto) ${ }^{34}$.

En 1676, en las prensas lionesas de los Anisson, de fray Martín vieron la luz dos obras de amplio espectro: la gramática hebrea, el Arte hebraispano, de que ya hemos hecho mención y una edición a partir de un manuscrito de la biblioteca Malatestiana de Cesena en Italia de los Sermones áureos de Pedro Crisólogo, obispo de Ravenna (m. 450), proclamado un siglo más tarde del trabajo de fray Martín como doctor de la Iglesia ${ }^{35}$. Esta edición plantea algunas preguntas interesantes que aún no he

30 Castillo, 1675: f. 73r-76r.

31 Orfali Levi, 1985, aunque no pudo contar con fuentes inéditas en el momento de la publicación de este artículo que quizá hubieran modificado sus conclusiones; Ciruelo, 1538: f. H1v-H9r (la foliación debe tomarse cum grano salis: el ejemplar de la Biblioteca Histórica Complutense, signatura BH FOA 632, tiene los folios descolocados; el registro del catálogo en línea de la Biblioteca Nacional de España, que da las siguientes signaturas de folio: $\mathrm{A}-\mathrm{G}^{8}, \mathrm{H}^{4}$, obvia que la última página, que concluye la quaestio paradoxica que aquí nos interesa, está fuera de esa cuenta) sobre el que puede verse Secret, 1959: 48-55. En el resto del artículo, Secret transcribe los folios que referencio de Ciruelo, 1538. Sobre el hebraísmo cristiano en general, disciplina que ha generado una importante y amplia literatura de investigación, véase especialmente: Idel, 2010.

32 Castillo, 1637: f. 36r (según la foliación a tinta, quizá contemporánea de la copia; a lápiz de grafito, probablemente más moderna, 26r: doy ambas foliaciones en lo sucesivo, separados por un signo de igualdad). No he podido consultar en Madrid el original de este manuscrito sino solo por reproducción. El contenido es misceláneo y las manos de los copistas, diversas. En consecuencia, no puede sacar de momento conclusiones sobre la organización interna del material o si las unidades textuales, que parecen tres (Castillo, 1637: f. 10r=2r36r=26r (primera unidad textual); f. 39r=28r-50r=39r (segunda unidad textual); f. 53r=42r-60r=49r (tercera unidad textual); f. $193 \mathrm{r}=50 \mathrm{r}-228 \mathrm{v}=84 \mathrm{v}$ (cuarta unidad textual); f. $229 \mathrm{r}=85 \mathrm{r}-235 \mathrm{r}=91 \mathrm{r}$ (quinta unidad textual); $\mathrm{f}$. $1 \mathrm{r}=236 \mathrm{r}=92 \mathrm{r}-8 \mathrm{r}=243 \mathrm{r}-99 \mathrm{r}$ (sexta unidad textual). A priori, solo la primera unidad textual es obra segura de fray Martín y, en puridad, quizá la segunda.

33 Castillo, 1637: f. $31 \mathrm{r}=21 \mathrm{r}$ y $32 \mathrm{r}=22 \mathrm{r}$.

34 Castillo, 1637: f. 32r-22r.

35 Castillo, 1676b. 
podido resolver: afirma en la portada que es edición del manuscrito cesenati pero, ¿cómo se hizo esa edición? ¿Acaso mediante un apógrafo del probable manuscrito tardomedieval al que se está refiriendo fray Martín ${ }^{36}$, o quizá estuvo un tiempo residiendo en Italia? Sea como fuere, fray Martín se aplicó a la frase del libro bíblico de Sabiduría (10:21) que inicia buena parte de las versiones conservadas del prefacio a los sermones de Crisólogo: linguas docentium fecit disertas ("y dio sonidos claros a las lenguas de los que enseñan") ${ }^{37}$. Y esto aun en las penosas circunstancias de lo que parece una grave enfermedad oftalmológica degenerativa ${ }^{38}$.

Ocho años, en 1684, en Colonia (Alemania) sale a la luz una curiosa obra de hagiografía polémica, si se me permite el retruécano, escrita sin embargo con buen estilo literario, y en lengua española: es el Diálogo traumático regular ${ }^{39}$. Aun en 1690, en Sevilla (disfrazada de Génova), el librero sevillano Juan Salvador Pérez saca a luz un tratado mariológico de profunda erudición bíblica en que el franciscano burgalés cifra la excepcionalidad de la figura de la Virgen María en las heroínas bíblicas (el término es del propio del Castillo: heroissae) Débora y Yael, a la vez que se produce una reedición del Diálogo traumático regular ${ }^{40}$.

Como se ve, por un lado, la obra de fray Martín no es solo útil para la historia del pensamiento novohispano sino para la historia del libro y de la edición en la Nueva España y, en general, para el ajetreo librario entre ambas orillas del Atlántico. Se conservan al menos cinco manuscritos de borradores previos a la impresión de obras de fray Martín, excepcionales testimonios del proceso de redacción y de edición de estas obras, incluyendo al menos cuatro que se publicaron en Europa ${ }^{41}$. Por otro lado, este corpus de escritos de nuestro franciscano es señal, de que para él y para la comunidad de conocimiento en la que se reconocía y de la que formaba parte, la de los teólogos católicos de la Edad Moderna, el hebreo era una herramienta auxiliar de primer orden cuya utilidad solo podía comprenderse a cabalidad en el contexto del humanismo bíblico altomoderno.

\section{Cábala y lectura hebraística en la Nueva España}

Un dato cultural nada menor es la posible existencia, en la Nueva España, de obras de cábala cristiana. De momento, el único registro de tal posibilidad es la presencia de un libro que un emprendedor librero sevillano expidió para el México colonial.

36 Olivar, 1962: 56 y nota 35.

37 La lectura habitual de las ediciones de la Vulgata es linguas infantium fecit disertas: "y dio sonidos claros a las lenguas de los infantes".

38 Según lo que él mismo explica en su prólogo al lector, Castillo, 1676b: f. *2v.

39 Castillo, 1684.

40 Castillo, 1690. El Genuae ("en Génova") de la portada se refiere, en realidad y como es habitual, a la sevillana calle Génova, tradicional sede de imprentas y del comercio del libro.

41 Son los manuscritos con número de signatura 350, 353, 560 y 1802. Véase Yhmoff Cabrera, 1975: 76-79 y 279280. Del ms. 1802 del RFO, BNM solo tengo noticia por Yhmoff Cabrera, 1975: 279-280, registro 402, puesto que no he podido consultarlo por el momento. Beristáin y Souza, 1883: 275, señala la presencia en Tlatelolco de un original manuscrito de la gramática griega de Martín del Castillo que no he podido localizar de momento. Por su parte, en la Biblioteca Armando Olivares de la Universidad de Guanajuato se conserva una transcripción manuscrita, probablemente un borrador, de otro de los libros impresos de Del Castillo. Agradezco al Ing. Francisco González, de la misma biblioteca guanajuatense, su inestimable y generosa ayuda para la consulta del fondo. 
De la treintena larga de obras de hebraística y orientalística que fueron embarcadas en 1600 en Sevilla con destino al puerto veracruzano de San Juan de Ulúa, documento bien conocido desde que hace más de medio siglo Irving Leonard lo diera a conocer ${ }^{42}$. Se encuentran obras de hebraística, incluyendo textos en arameo (targum), que Leonard, en su estudio, no examina críticamente y en algún caso importante, como el libro de cábala, no consigue identificar ${ }^{43}$. Entre los libros que hallamos en esa lista encontramos, como era de esperar, la gramática y el diccionario de Sante Pagnini ${ }^{44}$; la gramática hebrea de Marco Marini, hebraísta e inquisidor ${ }^{45}$; la gramática del converso alemán Johann Isaac Levita ${ }^{46}$; la edición de la paráfrasis aramea canónica de la Biblia hebrea, es decir, el Targum ${ }^{47}$; o tratados polémicos de catequización de neófitos de origen judío, en lengua italiana ${ }^{48} ; \mathrm{y}$, el descubrimiento que nos parece de una notable relevancia en términos culturales, la traducción latina de un tratado clásico de la cábala judía medieval ${ }^{49}$. Es una auténtica biblioteca del hebraísta que se enseñorea de las tradiciones escritas en hebreo y arameo por y para judíos en un esfuerzo de translatio euangelica. Es, pues, una biblioteca a la fuerza de teólogos ${ }^{50}$. Ese es el público probable de estas obras que constituyen volúmenes reconocidos en el mercado librario destinado a los estudiosos en la época, obras que en algún caso, como el de Pedro Martínez de Morentín, hugonote navarro, también presente en esta lista, o la edición latina del Targum de Onqelos, obra del profesor de teología protestante en Estrasburgo Paulus Fagius, da muestras de algo en absoluto desconocido para la Nueva España: la circulación de obras producidas por autores protestantes. Antes que la confesión de los autores, interesa la utilidad de sus obras. Auctor damnatus opusque permissum, como rezaba la fórmula inquisitorial.

Tenemos en este conjunto de ediciones una de las características que parecen haber marcado el estudio del hebreo en la Nueva España: la circulación constante y actualizada de las obras de más reciente factura y la incorporación del estudio del hebreo y del arameo como uno de los constituyentes de la cultura intelectual del México colonial, verdadero punto de encuentro de un diálogo transatlántico de saberes del que queda mucho por recuperar.

42 Leonard, 2006: 328-344 y 456-487. El documento original es el Archivo General de Indias (AGI), Contratación, legajo 1.135, folios 153r-169v, que he consultado en la reproducción digital disponible en el Portal de Archivos Españoles (PARES).

43 Traté e identifiqué las gramáticas incluidas en esa lista en Prado Plumed, 2014. El capítulo fue víctima de un proceso editorial de una supina incompetencia que mutiló párrafos enteros (incluido el primero), trastocó los datos de los apéndices e hizo irreconocible mi trabajo. Ameritará una reedición, revisada y puesta al día, en mejor ocasión y con mejores editores.

44 Pagnini, 1529, 1549, respectivamente.

45 Marini, 1585.

46 Bien Isaac Levita, 1557, del que se conoce al menos un ejemplar de procedencia novohispana, hoy (de milagro, pues estuvo inencontrable durante al menos tres años) en la Biblioteca Nacional de México, o Isaac Levita, 1558 .

47 Fagius, 1546. Existe un ejemplar de esta edición en la Biblioteca Palafoxiana de Puebla.

48 Fioghi, 1582.

49 Ricius, 1516. Entre las varias ediciones de algunas de estas obras, optamos por el criterio, completamente arbitrario, de seleccionar la de fecha más cercana a la de este embarque de libros. El total de ediciones hebraísticas presentes en esta lista de libros excede la treintena.

50 García-Jalón de la Lama, 1998: 70. 


\section{Exégesis, filología bíblica y "judíos nuevos”}

En el otoño de 2016, una noticia inesperada aunque muy deseada por la comunidad de historiadoras e historiadores académicos se divulgó a través de los medios de comunicación masivos de los Estados Unidos de América a los Estados Unidos Mexicanos: los manuscritos supuestamente robados en 1932 del Archivo General de la Nación, conservados dentro de los legajos del proceso inquisitorial, que lo condujo a la hoguera, de Luis Rodríguez de Carvajal, "el Mozo", (que se nombró a sí mismo con su nombre judío de José Lumbroso) habían reaparecido como uno de los lotes puestos a la venta en una casa de subastas estadounidense. Por mediación del filántropo también estadounidense y de confesión judía Leonard L. Milberg, el gobierno mexicano, a través de su representación diplomática en Estados Unidos, consiguió el regreso de los manuscritos que, sorpresivamente, no acabaron en su repositorio de origen, el Archivo General de la Nación, sino en la Biblioteca Nacional de Antropología e Historia. En el momento de redactar estas líneas, ahí se conservan aunque pareciera que su destino último está en discusión ${ }^{51}$. La restitución de estos manuscritos abre una amplia ventana de posibilidades de investigación. A simple vista, los manuscritos y en especial la famosa "autobiografía" (vida) de Luis "el Mozo" confirman algunas de las afirmaciones que los documentos del proceso hacían sobre Luis. Por ejemplo, su admirable calidad de pendolista. Pero también lo profundo y variado de su erudición exegética, basado en lecturas netamente cristianas pero vueltas de revés por el espejo deformante de una religiosidad judía clandestina "imaginada", es decir, recreada, propia de las comunidades sefaradíes constituidas de la diáspora occidental sefaradí o de los grupos clandestinos de criptojudíos que nunca consiguieron cuajar como comunidades viables, como es el caso de las formadas y conocidas en las colonias americanas de la Monarquía católica hispánica y de Portugal. Sin duda, estos manuscritos nos irán relevando aspectos desconocidos de la trayectoria vital, ideológica y espiritual de Carvajal "el Mozo", nos irán confirmando otros aspectos y refutarán ideas concebidas a la luz de lo disponible en la más que discutible transcripción de Alfonso Toro, el único texto disponible hasta 2016 $6^{52}$. Algunas características del mundo espiritual e intelectual de Carvajal se revelan hasta cierto prudentes en una primera observación de los manuscritos. Por ejemplo, el papel del portugués, que aparece en varios lugares del manuscrito en textos de los varios no transcritos por Toro, quien pareció conformarse con el texto de lo que consideró la Vida de Carvajal, despreciando (o, más probablemente, no entendiendo) los demás ${ }^{53}$.

51 Según da a entender en una entrevista radiofónica de enero de 2018 el actual director de esa biblioteca, Baltazar Brito. Desde julio de 2018 un equipo multidisciplinar e internacional, compuesto por Ronnie Perelis, Berenise Bravo Rubio y quien subscribe, nos hemos puesto a la tarea de preparar la edición crítica de esos manuscritos, con estudio histórico y traducción al inglés.

52 El manuscrito digitalizado con notable calidad está disponible en la página web de la Universidad de Princeton, por expreso deseo de Leonard Milberg. La URL de referencia es: http://arks.princeton.edu/ark:/88435/ s7526g29j Como indica la propia web, las imágenes fueron tomadas en la New York Historical Society, mientras los manuscritos estaban en exhibición en el marco de la exposición "The first Jewish Americans", de octubre de 2016 a marzo de 2017. Al término de esta exposición, donde habían sido expuestos de nuevo por expreso deseo del señor Milberg dentro del acuerdo de repatriación de estos materiales, los manuscritos fueron finalmente devueltos a México donde llegaron, por cierto recibidos con abundante fanfarria mediática, en la primavera de 2017.

53 Citando de momento por el número de las imágenes de la reproducción digitalizada, pues la mayor parte de los folios no están foliados, podemos mencionar las páginas 172, 173 y 174 en que el manuscrito transmite todo una serie de textos, entre edificantes y devocionales, en portugués, aunque a primera vista con soluciones gráficas 
Este lugar de la lengua portuguesa como locus privilegiado de una religiosidad clandestina, criptojudía, no es desde luego una sorpresa, dado entre otras cosas el origen familiar de los Carvajal y de su familia extendida, pero es una característica en la que hasta ahora no se había hecho demasiado hincapié ${ }^{54}$.

Por otro lado, y a partir de la transcripción de que hemos dispuesto desde los años 30 del pasado siglo, se conocía las amplias lecturas de Luis de Carvajal sobre todo a partir de su inclusión entre los empleados por el convento de Tlatelolco ${ }^{55}$. La llegada a la "librería" de Tlatelolco de las obras del clásico exegeta hebraísta medieval Nicolás de Lira tanto como la lectura profunda ("sacarle las moralidades") del monumental comentario al Pentateuco del también exegeta hebraísta (e inquisidor) Jerónimo de Azambuja (ab Oleastro) redunda en una abierta alegría de nuestro converso judaizante:

[...] y por que se noten las misericordias del Señor es de notar que para cumplir su divina majestad a Joseph el deseo bueno que había tenido diciendo a su compañero que estaba preso, quien me diera en una de esas librerías ordenó que este fraile le diese una llave de la celda en que tenía todos sus libros en el colegio dicho [de Tlatelolco] quedando él con la otra, lo cual no hacía con ninguno de sus compañeros frailes, porque esta merced del Señor fuese más colmada de su liberalísima magnificencia, no había cuatro meses que Joseph allí estaba, cuando ordenó que el fraile mismo comprase la glosa de [Nicolás de] Lira, declaración de la Sagrada Biblia en cuatro grandes cuerpos, de la librería de un gran predicador de su orden que había muerto, y cuando se los trujeron le vino el mismo como a pedir las albricias y Joseph diciéndole: ¡oh, qué ricas colegio!; de los cuales dones del muy alto Dios, Joseph con gran cuidado se aprovechaba, porque el tiempo que el fraile se iba a comer y todos los colegiales a sus casas se quedaba él con las llaves del colegio dentro del encerrado leyendo y trasuntando en romance muchas cosas de la Biblia sagrada en que iba recogiendo matalotaje para el ánima, temiéndose de la cárcel y adversidad que el Señor le escapó con muchos milagros; también el tiempo que le sobraba después de la lección de los estudiantes le ocupaba el fraile en sacarle las moralidades de [Jerónimo de Azambuja, es decir, Hieronymus ab] Oleastro sobre el Pentateuco $0^{56}$ en orden y tablas por el alfabeto, el cual ejercicio era tan conforme a su inclinación y buen deseo, que si diera por él la sangre no lo

propias del castellano, quizá de forma no siempre homogénea. Como decimos, este es un primerísimo examen preliminar que necesita una edición propiamente crítica ulterior.

54 Así ocurre, igualmente, con el proceso de otro de los implicados, Gonzalo Pérez Ferro, legajo de cuya existencia no se tenía noticia y que fue adquirido por la Universidad de Pensilvania en Filadelfia hace menos de cuatro años. El volumen, encuadernado modernamente, está disponible en un facsímil digitalizado en línea, siendo la signatura topográfica del mismo Filadelfia, Universidad de Pensilvania, ms. 56, codex 001.1, URL: http:// hdl.library.upenn.edu/1017/d/medren/9950188923503681. El proceso conserva diversos textos autógrafos de Pérez Ferro que demuestran una alfabetización solo parcial en castellano, una caligrafía poco diligente y un idiolecto castellano de obvia interferencia portuguesa, que más que desvelar un substrato, apunta a un deficiente conocimiento y a una falta de interiorización de las estructuras profundas de la lengua castellana, sintácticas y morfológicas, lo que nos lleva a pensar, no solo que la lengua materna de Pérez Ferro era el portugués, algo por lo demás obvio, sino que no necesitaba para su vida en México desempeñarse de forma más competente en la lengua española del país. Sobre la cuestión general de los judeoconversos portugueses en la Monarquía Católica, véase Bodian, 1994 y, para la Nueva España, los apuntes sobre el tema ofrecidos en León Portilla, 2005.

55 Toro, 1944, t. II: 315-339.

56 Es decir, sus Commentaria in Pentateuchum Mosi, de los que durante el siglo XVI se publicaron ediciones en Lisboa en 1556, Amberes en 1568 y 1569 y Lyon en 1586, 1588 y 1589. 
pagaba sea el Señor bendito y ensalzado quien ansí agrada a los buenos deseos, en este libro le descubrió el Señor los santos trece artículos y fundamentos de nuestra fee y religión ${ }^{57}$, cosa no sabida y oída en las tierras de captiverio ${ }^{58}$.

Nicolás de Lira es uno de los principales exegetas cristianos de la Baja Edad Media y recurre a las fuentes hebreas y a las tradiciones judías de forma sistemática y constante $^{59}$. Las copias de sus obras en época manuscrita y las ediciones en época ya de la imprenta, incluidas las españolas, son numerosísimas; su popularidad hasta por lo menos el siglo XVII, inmensa. Por su parte, Jerónimo de Azambuja fue sin duda uno de los comentaristas más prestigiosos y exhaustivos de su época aunque haya caído, prácticamente, en el olvido.

En la argumentación retórica que cimenta el texto de la Vida que compone Carvajal, es un episodio central, según él nos narra, cuando consigue el acceso, a medias disimulado, a los textos de exégesis, teología y biblística de la biblioteca ${ }^{60}$. Son lecturas a contrario, como son las que cimentan esa nueva identidad religiosa de los que se ha dado en llamar "judíos nuevos" o, si se prefiere y siguiendo el modelo propuesto por Benedict Anderson para las identidades (en su caso nacionales) colectivas, "judíos imaginados" se leerá la nueva devoción, clandestina y herética visto desde la ortodoxia cristiana, del criptojudaísmo ${ }^{62}$. Esta es justamente la operación intelectual que aquí nos describe, con lujo de detalles, Carvajal desde esa última Thule tropical de la erudición occidental que era entonces el continente americano colonizado. Porque Carvajal, de probable educación jesuita en su Castilla natal, es un hombre y un lector occidental, educado en la tradición cristiana de lectura, de exégesis y de biblismo, y su epifanía textual se enmarca en el ámbito de lo que se podía esperar de un humanista bíblico desde, por lo menos, el siglo XV: lectura detallada de los textos, echar mano de las mejores autoridades (Lira, Azambuja), mismas que, a su vez, recurrían a la lectura comentada de las fuentes escriturísticas en las lenguas originales, hebreo y griego fundamentalmente. Es este mundo de biblismo filológico apegado a las fuentes que nos interesa explorar en las siguientes páginas, acuciados por las lecturas de los textos redescubiertos de Carvajal. ¿Cuáles son los horizontes de esa erudición? ¿Cuáles sus objetivos? ¿Cuáles sus posibles límites particularmente en el contexto de la América Latina colonial con especial atención a los reinos novohispanos? Existe la idea bastante extendida de que lo hebreo, como vehículo escriturístico y cultural, y judeoconverso o incluso criptojudío son casi sinónimos. No lo son. A título de ejem-

57 Es decir, los trece principios ('iqqarim) formulados en la Edad Media por Maimónides, aunque parece que Carvajal desconocía la autoría de esa síntesis. En una de las ediciones que pudo haber manejado Carvajal (más probablemente la de Amberes o Lyon que la de Lisboa), la referencia se encuentra en Azambuja, 1588: 517 (f. Bb514r): “Audi Israel Dominus Deus noster, Deus vnus. Habent Iehudaei 13. articulos fidei, quos tredecim vocant fundamenta". Como se ve, Azambuja no desvela el origen maimonidiano de esta lista, que no debía serle sin embargo desconocido.

58 Toro, 1944, t. II: 328-329. Modernizo la ortografía, salvo en el caso de "Joseph", y la puntuación y desarrollo las abreviaturas. Las "tierras de captiverio" son aquellas, como el México colonial o en general el imperio de los Habsburgo hispánicos, donde la práctica del judaísmo estaba prohibida.

59 Copeland Klepper, 2007.

60 González González - Gutiérrez Rodríguez, 2015.

${ }^{61}$ La expresión "judíos nuevos” es de Yosef Kaplan, en formulación que tiene algo de sutil ironía respecto de la clásica discriminación entre "cristianos viejos" y "nuevos” en la península Ibérica desde finales del siglo XV. Véase Kaplan, 2000.

62 Yerushalmi, 1989; Vega Ramos, 2010; Vizán, 2013. 
plo, Nicolás de Lira, Ramon Llull o Ramon Martí, en la Edad Media, o Jerónimo de Azambuja, Francisco de Quevedo, Martín Martínez de Cantalapiedra o Pedro Martínez de Morentín, algunos católicos, otros protestantes, algunos ibéricos, otros oriundos de allende los Pirineos, no fueron nunca tildados de "judíos" (es decir, de convertidos) ni por sus contemporáneos ni por su posteridad. Y son todos, sin excepción, celebrados hebraístas. Lengua hebrea, filiación genealógica y adscripción intelectual, teológica o espiritual no van de la mano como condiciones sine qua non. Antes al contrario, puede ser una condición coadyuvante a una búsqueda espiritual que vehicule una inquietud religiosa, hasta llegar a casos como el del malogrado Lope de Vera y Alarcón, reconocido por la opinión como cristiano viejo, y sin embargo quemado por judaizante en Valladolid en 1644 después de un proceso de conversión a la fe judía que él mismo elucubró sin ningún antecedente genealógico ni converso ni criptojudío. Es decir, lo importante tanto en el caso de Luis Rodríguez de Carvajal, "el Mozo", como en el de Lope de Vera y Alarcón, no es tanto la filiación genealógica o incluso la posible transmisión familiar del criptojudaísmo, como afirma Carvajal en su Vida sobre sí mismo ${ }^{63}$, sino en la participación entusiasta en una forma concreta de espiritualidad de la época, el pietismo bíblico que tiene, en la España del siglo XVI, expresiones netamente protestantes, como es el caso de Miguel Serveto o de los llamados jerónimos "isidros" del convento de San Isidoro del Campo en Santiponce, en las cercanías de Sevilla, donde entre otros profesó y se hizo protestante Casiodoro de Reina, autor de la Biblia del Oso ${ }^{64}$.

En segundo lugar, proporcionar algunas pistas que sirvan para desbrozar las sendas que pudo seguir el cultivo del hebreo, como disciplina humanística y teológica, en la Nueva España. Me planteo si el caso novohispano puede servir de modelo para otros en la América Latina colonial. Una primera respuesta, tentativa y provisional a la vista de los primeros resultados incipientes que he recabado en Bogotá o, por noticias indirectas, Lima, Cuzco y Córdoba (Argentina), parece ser positiva: la práctica del hebreo y, más aún, de la lectura de obras católicas de exégesis bíblica, fundamentadas en la veritas hebraica y aún en las "glosas de los rabinos", es decir, en las traducciones de comentarios rabínicos fundamentalmente medievales o en la cita de estos comentarios en las obras de autoría católica, fue un elemento más, y perfectamente común, del paisaje intelectual de los siglos coloniales en la América hispánica.

\section{Conclusiones y perspectivas de investigación}

El estudio del hebraísmo cristiano y la reevaluación de su importancia en el ámbito intelectual del mundo occidental del Antiguo Régimen (siglos XVI, XVII y XVIII) es una línea de investigación de plena actualidad que está dando en los últimos años frutos notables. En la Edad Moderna, el hebraísmo cristiano es, junto con el helenismo, una de las dos ramas principales del humanismo políglota, es decir, la indagación de los textos constitutivos de la tradición occidental en las lenguas que preservan los testimonios más antiguos de esos textos.

\footnotetext{
63 " $[\ldots]$ y como la verdad de Dios es tan clara y agradable no fue menester más que advertirle de ella su madre, hermano y hermana mayores y un primo suyo de la dicha villa". Toro, 1944, t. II: 316.

64 Bada Prendes, 2016.
} 
Hasta la fecha no se ha emprendido una exploración sistemática y exhaustiva de la presencia del hebraísmo cristiano ni del cultivo del griego en la Nueva España ${ }^{65}$. Sin embargo, hay indicios de que esas disciplinas intelectuales se cultivaron con particular esmero en los círculos eruditos novohispanos. Así, como si fuera un remedo de un Ogerio novohispano ${ }^{66}$, Cayetano de Cabrera y Quintero (ca. 1700-ca. 1774) ${ }^{67}$ habría publicado "una gramática al mismo tiempo hebrea que griega", como señala Juan José de Eguiara y Eguren ${ }^{68}$.

Aparte de estas noticias, principal índice histórico que se nos conserva de esta actividad intelectual de hebraística y helenística cristiana en el antiguo virreinato son los volúmenes que tratan, de cerca o de soslayo, esta temática, que se documentan en bibliotecas novohispanas. Esta evidencia bibliográfica puede sustanciarse con dos afirmaciones: en primer lugar, la propia existencia de los volúmenes en los actuales acervos bibliográficos o su mención en registros de archivos. En segundo lugar, la constatación de marcas de lectura en los volúmenes, testimonio del uso que tuvieron esos ejemplares ${ }^{69}$. Esta indagación es susceptible de aplicarse a otros ámbitos históricos de la América Latina colonial. El cultivo del hebreo no era un dato extravagante en una dedicación anticuaria de eruditos ociosos sino un elemento fundador y fundamental de los paradigmas de conocimiento, en especial del humanismo y la filología bíblicos, que formaban el tuétano de la actividad intelectual, institucional o particular, de los sabios radicados en las Indias de Castilla. Este es un primer esbozo que pretende exponer la obvia riqueza documental que estas prácticas intelectuales legaron como patrimonio, en primer lugar bibliográfico. Es hora de integrar estos saberes a las prácticas de las historiadoras e historiadores intelectuales de la América Latina colonial. La escritura de la historia cultural e intelectual de este continente donde escribo estas líneas tiene tiempo que se demostró políglota, multicultural, diversa y rica. Ahora tenemos que integrar el hecho de que se pueda empezar a escribir, también, de derecha a izquierda ${ }^{70}$.

\section{Referencias bibliográficas}

Alston, Robin C. Books with manuscript. A short-title catalogue of books with manuscript notes in the British Library, including books with manuscript additions, proofsheets, illustrations, corrections [1993]. London: The British Library, 1994.

65 Como ejemplo de trabajo incipiente pero sólido, puede verse Osorio Romerio, 1986, luego reeditado como Osorio Romerio, 1989.

66 Ogerio, 1764. No he encontrado ejemplares de esta obra en bibliotecas mexicanas o en los catálogos, listas e inventarios de bibliotecas pretéritas que he podido consultar.

67 Sobre Cabrera y Quintero, véase Herrera Zapién, 1993. El RFO de la BNM conserva una notable cantidad de material de este autor, entiendo que en su mayoría inédito, cuya referencia sería ocioso señalar en el presente trabajo.

68 Tomo la referencia, la cita y la traducción de Osorio Romerio, 1986: 80, "Una gramática, es decir, un arte para aprender tanto hebreo como griego, cuyos alfabetos se describen en verso heroico latino [hexámetro]: con no poco trabajo reunió ambas [lenguas] en una obra sobradamente amplia de poco volumen, en la que el autor dispuso en verso todo lo que está prescrito de los principios y la pronunciación del dialecto de cada idioma".

69 Sobre el estudio de las marcas de lectura, véase, a título de ejemplo no exhaustivo, Alston, 1994 [1993]; Llamas Martínez, 1986; Molekamp, 2006; Sherman, 2009.

70 Es decir, de forma "sinistrorsa". 
Andrés Castellanos, Enriqueta de. Helenistas españoles del siglo XVII. Madrid: Fundación Universitaria Española, 1988.

Arias Montano, Benito. ELVCIDATIONES / IN QVATVOR / EVANGELIA, / MATTHAEI, / MARCI, / LVCAE \& / IOHANNIS / Quibus accedunt eiusdem elucidationes in Acta Apostolorum. ANTVERPIAE: Ex officina Christophori Plantini / Architypographi Regij., 1575. Ejemplar consultado: Madrid, Universidad Complutense, Biblioteca Histórica Marqués de Valdecilla, BH DER 62.

Azambuja, Jerónimo de. ELENCHVS / COMMENTA/RII IN PENTATEV/CHVM HIERONYMI / AB OLEASTRO, / Seu potius eorum quae ab auctore acute, \& pru-/denter in hoc libro considerantur, singulis Euan/gelijs quae per annum decantantur \& praedican-/tur, tan [sic] de te [m]pore quam de sanctis, accura/ta acco[m] modatio, omnibus verbi diuini / ce[n]cionatoribus vtilissima. BARCINONE (=Barcelona), 1588. Ejemplar consultado: Ciudad de México, Biblioteca Nacional de México, Fondo Reservado, RFO 222.107 AZE.e. 1588.

Bada Prendes, Constantino. "La Biblia del Oso de Casiodoro de Reina; primera traducción completa de la Biblia al castellano". Tesis doctoral, Universidad Pontificia de Salamanca, 2016.

Beristáin y Souza, José Mariano. Biblioteca hispano americana setentrional [1816], vol. 2. Amecameca: Publícala el presbítero Br. Fortino Hipólito Vera [...] Tipografía del Colegio Católico, 1883.

Bodian, Miriam. "'Men of the Nation': The shaping of Converso identity in early modern Europe". Past \& Present, no 43 (1994), 48-76. DOI: 10.2307/651161

- Dying in the law of Moses: Cripto-Jewish martyrdom in the Iberian world. Bloomington: Indiana University Press, 2007.

Campanini, Saverio. "Peculium Abrae. La grammatica ebraico-latina di Avraham de Balmes". Annali di Ca' Foscari, vol. 36 (1997), 5-49.

Castillo, Martín del. Conclusiones Biblicae / EN EL COLLEGIO IMPE=/RIAL DE LA $C O M=/ P A \tilde{N} I A D E$ JE=/SVS / SABADO 23 DE / MAYO / A las 3 de la tarde / Año de 1637. 1637. (MSS 6540). Biblioteca Nacional de España, Madrid.

- ARS BIBLICA / SIVE / HERMA MEMORIALIS / SACRA / IN QVA / Metricè S. Paginae libri, capita, eorumque / medulla, memoriae facillimè commendantur. / Restituta, recognita, aucta, ab innumeris, quibus / scatebat mendis, expurgata, \& iuxta Concilij Tridentini / formam correcta [...] Eiusdem Authoris Scholijs, sivè argumentis, / in quibus diuinorum Codicum Scriptores, capita, \& versus / recensentur: cumque XXX. quaestionum (pro generali Sacrorum Bibliorum intelligentiâ) brevi resolutione: \& / Catalogo primariorum Doctorum, cum Priscorsum, / tum Recentiorum, qui super omnia diuini / Oraculi scripsêre volumina. MEXICI (=México): sumptibus Francisci Rodriguez Lupetij, 1675. Ejemplar consultado: Ciudad de México, Biblioteca Nacional de México, Fondo Reservado, 1675 M4CAS.

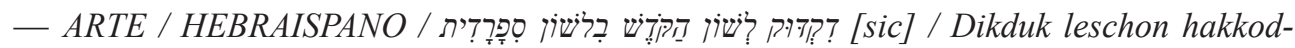
hesch bilschon sipharadhith / GRAMMATICA / DE LA LENGUA SANTA / EN IDIOMA CASTELLANO [...] Con todo lo necessario y preciso, pára por si sólo, / qualquiér afficionádo, podér leér, escribir, / entendér, y hablár la léngua santa Hebréa. EN LEON DE FRANCIA [= Lyon]: A Costa de FLORIAN ANISSON, / Mercader de Libros en Madrid, 1676a. Ejemplar consultado: Ciudad de México, Biblioteca Nacional de México, Fondo Reservado, RFO 492.45 CAS.a. 1676.

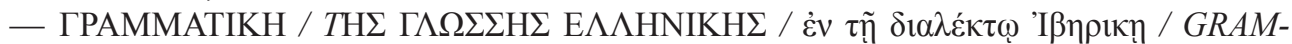
MATIKEE / têes Glóossees Helleenikees en teê / dialectoo Ibeerikêe / GRAMMATICA / 
DE LA LENGUA GRIEGA, / en Idioma Español [...] Con tódo lo necessario, pára podèr por si solo / qualquièr afficionádo, leèr, escrebir, / pronunciàr, y savèr la generàl y muy / noble Lengua Griéga. EN LEON DE FRANCIA: A costa de FLORIAN ANISSON, / Mercader de Libros en Madrid, 1678. Ejemplar consultado: Ciudad de México, Biblioteca Nacional de México, Fondo Reservado, RFO 185 ARI.d.4 1603.

- DIALOGO / TRAVMATICO REGVLAR, / EN EL QVAL, / VNA PARTE HABLAN / TRES REVERENDOS PADRES DEL ORDEN DE N[UESTRO] GRAN PADRE SANTO DOMINGO, COMO / CENSORES DE VN TRATADO INTITVLADO, / EL HVMANO SERAPHIN, Y VNICO LLAGADO; / De como solo el glorioso Patriarcha Padre N. S. Francisco, entre todos los Santos de la Iglesia, goza, y possee las llagas, pe-/netrantes, cruentas y visibles de N. Señor Jesv Christo [...] VA A LO VLTIMO IMPRESSO EL REFERIDO TRATADO / Apologetico, para que mejor sea juzgada la Verdad. En Colonia Agripina (=Köln): Por Juan Baseo, Mercader de Libros, 1684. Ejemplar consultado: Ciudad de México, Biblioteca Nacional de México, Fondo Reservado, R 922.245 FRA.ca. SAN 1690.

- TRACTATVS PANEGYRICVS / DE SANCTISSIMA MARIA DOMINA NOSTRA / IN DEBBORA ET JAHELE / VETERIS TESTAMENTI HEROISSIS, / \& celebratissimis Feminis coelitùs adumbrata. I Ad Caput IV. \& V. Libri Judicum. / Additi sunt ad calcem Illustrationum Panegyricarum Sermones sex, juxta / moralem historia Debbora \& Jahelis sensum, / pro Concionibus Vespertinis in Quadragesima concinnandis. / Cum Indicibus quinque [...] / NUNC PRIMUM IN LUCEM PRODIT. GENVAE: Sumptibus JOANNIS SALVATORIS PEREZ, / Hispalensis Bibliopolae, 1690. Ejemplar consultado: Ciudad de México, Biblioteca Nacional de México, Fondo Reservado, RFO 232.91 CAS.t. 1690.

- ARS BIBLICA, / SIVE / HERMA MEMORIALIS / SACRA / IN QUA / Metricè S. Paginae libri, capita, eorumque / medulla memoriae facillimè commendantur. / Restituta, recognita, aucta, ab innumeris, quibus / scatebat mendis, expurgata, \& juxta Concilii Tridentini formam correcta [...] / CUM / Ejusdem Autoris Scholiis, sivè argumentis, / in quibus divinorum Codicum Scriptores, capita, \& / versus recensentur: cumque XXX. quaestionum (pro / generali Sacrorum Bibliorum intelligentia) brevi re-/solutione: \& Catalogo primariorum Doctorum, cum / Priscorum, tum: Recentiorum, qui super omnia diuini Oraculi scripsere volumina. / Opus olim Mexici lucem editum, nunc verò denuò. ASTIGI (=Écija): typis mandatum sumptibus Benedicti Daza hujus Civititatis Typographi, 1778. Ejemplar consultado (en línea): Barcelona, Biblioteca Pública Episcopal del Seminari, 3.6.106.

- (ed.). DIVI PETRI / CHRYSOLOGI / ARCHIEPISCOPI RAVENNATIS / SERMONES AVREI / AD EXEMPLAR SERAPHICAE / Cesenae Bibliothecae Correcti, Scholiis, ac / locupletissimis moralium Conceptuum / varietate Commentariis illustrati / NVNC RECENS IN GRATIAM DIVINI VERBI / Concionatorum, additâ Sanctissimi Doctoris Vitâ, necnon \& eiusdem / ad Eutychetem Epistolâ Notis pariter elucidatâ, / prodeunt in lucem. LVGDVNI (= Lyon): Sumptibus FFr. ANISSONIORVM \& IOAN. POYSVEL, 1676b. Ejemplar consultado: Ciudad de México, Biblioteca Nacional de México, Fondo Reservado, RFO 252.008 PET.sa. 1676.

Ciruelo, Pedro. PARADOXAE QUAESTIONES NV/mero decem: ex officina Magistri Petri Cirueli / Darocensis nunc dempromptae. / De modis significandi dictionum in grammatica. / De dicibilibus transcendentibus \& limitatis in logica. / De uirtute actiua agentis naturalis in physica. / De potentia motiua corporis naturalis, etiam physica. / De rarefactione \& condensatione corporum, adhuc physica. / De arte Raymundi Lulii in methaphysica. / De loco paridisi terrestris a deo consiti, in cosmographia. / De tertia lege spiritus sancti circa finem mundi: in theologia. / De multiplicatione sensus literalis, in sacra scriptura. / De cabala \& magia Iudeorum in enarranda diuina biblia. Absolutum est hoc 
paradoxicum opusculum: in alma / Salmanticensium Achademia [sic] (=Salamanca, Universidad): [Gundisalvus de Castañeda], 1538. Ejemplar consultado: Madrid, Universidad Complutense, Biblioteca Histórica Marqués de Valdecilla, BH FOA 632.

Coelho, Ilda Sobral. "Frei Jerónimo de Azambuja: exegeta e hebraísta português". Cadmo. Revista do Instituto Oriental Universidade de Lisboa, vol. 11 (2001), 101-121.

Copeland Klepper, Deeana. The insight of unbelievers: Nicholas of Lyra and Christian reading of Jewish text in the later Middle Ages. Philadelphia: University of Pennsylvania Press, 2007.

Dunkelgrün, Theodor. "The Christian study of Judaism in early modern Europe". En The Cambridge History of Judaism, editado por Karp, Jonathan - Sutcliffe, Adam. Cambridge: Cambridge University Press, 2017, 316-348.

Fagius, Paulus. THARGVM / HOC EST / PARAPHRASIS / ONKELI CHALDAICA IN SA-/ CRA BIBLIA, EX CHALDAEO / IN LATINVM FIDELISSIME VER-/sa, additis in singula ferè Ca-/pita succintis Annota-/tionibus [...]. Argentorati: PER GEORGIVM MACHAEROPOEVM, 1546. Ejemplar consultado: París, Bibliothèque National de France, Réserve des livres rares (Tolbiac), A-670.

Fioghi, Fabiano. Dialogo fra il cathecumeno e il padre cathechizante. In Roma: per gli heredi d'Antonio Blado sta[m]patori Camerali, 1582. Ejemplar consultado: Madrid, Universidad Complutense, Biblioteca Histórica, Marqués de Valdecilla, BH DER 57.

García-Jalón de la Lama, Santiago. La gramática hebrea en Europa en el siglo XVI: guía de lectura de las obras impresas. Salamanca: Servicio de Publicaciones de la Universidad Pontificia de Salamanca, 1998.

— "La primera gramática hebrea en lengua española". Helmantica: Revista de filología clásica y hebrea, vol. 55 (2004), 59-72.

García Blanco, Antonio María. דקדוק / Análisis filosófico de la escritura y lengua hebrea. Madrid: Imprenta y fundición de Don Eusebio Aguado, 1846.

Garibay Kintana, Ángel María. "El P[adre] Castillo”. El Universal, (1955a, 5 de septiembre), $3,17$.

— "Hebraísmo en México". El Universal, (1955b, 12 de septiembre), 3, 17.

— "Zona de nadie". El Universal, (1955c, 29 de agosto), 3, 23.

González González, Enrique - Gutiérrez Rodríguez, Víctor. "Una biblioteca de latinidad para indios caciques: Santa Cruz de Tlatelolco (México, s. XVI)". En Università e formazione dei ceti dirigenti. Per Gian Paolo Brizzi, pellegrino dei saperi, editado por Angelozzi, Giancarlo - Guerrini, Maria Teresa - Olmi, Giuseppe. Bologna: Bononia University Press, 2015, 199-223.

González Laporte, Verónica. "La Semana Santa cora: expresión de identidad indígena”. Société suisse des Américanistes/Schweizerische Amerikanisten-Gesellschaft, vol. 64-65 (2000-2001), 117-122.

Grafton, Anthony. "Christian Hebraism and the rediscovery of Hellenistic Judaism". En Jewish culture in early modern Europe. Essays in honor of David B. Ruderman, editado por Cohen, Richard I. - Dohrmann, Natalie B. - Shear, Adam - Reiner, Elchanan. Pittsburgh: Hebrew Union College Press, University of Pittsburgh Press, 2014, 169-180.

Grafton, Anthony -Weinberg, Joanna. I have always loved the Holy Tongue. Isaac Casaubon, the Jews, and a forgotten chapter in Renaissance scholarship. Cambridge, London: The Belknap Press of Harvard University Press, 2011.

Herrera Zapién, Tarsicio. "Cayetano de Cabrera y Quintero, discutido vate neolatino (n. 1700 ?-m. después de 1774)". En Juan José de Eguiara y Eguren y la cultura mexicana. México, D.F.: Universidad Nacional Autónoma de México, 1993, 89-97. 
Idel, Moshe. Cábala hebrea y cábala cristiana. Buenos Aires: Lilmod, 2010.

Isaac Levita, Johannes. לשון למודים / Perfectissima hebreae grammatica commodo admodum ordine in tres libros distincta. Coloniae [Köln]: Ex officina typographica Iacobi Soteris, 1557. Ejemplar consultado: Ciudad de México, Biblioteca Nacional de México, Fondo Reservado, RFO 93-48867.

Isaac Levita, Johannes. הגיונות / MEDITATIONES / HEBRAICAE IN ARTEM GRAM/MATICAM PER INTEGRVM LIBRVM RUTH / explicatae, vnà cvm aliarum rerum nonnullis ac-/cessionibus, huius linguae tyronibus cum primis / vtilibus ac necessariis [...]. COLONIAE: Ex officina typographica Iacobi Soteris, 1558. Ejemplar consultado: Ciudad de México, Biblioteca Nacional de México, Fondo Reservado, RFO 492.4 ISA.g.

Kaplan, Yosef. "An alternative path to modernity". En An alternative path to modernity: the Sephardi Diaspora in Western Europe. Leiden: Brill, 2000, 1-28.

Kremers, Heinz - Siegele-Wenschkewitz, Leonore - Klappert, Bertold (eds.). Die Juden und Martin Luther, Martin Luther und die Juden: Geschichte, Wirkungsgeschichte, Herausforderung. Neukirchen-Vluyn: Neukirchener Verlagsgesellschaft, 1985.

León Portilla, Miguel. "Presencia portuguesa en el México colonial". Estudios de Historia Novohispana, vol. 32 (2005), 13-27.

Leonard, Irving A. Los libros del conquistador. México, D.F.: Fondo de Cultura Económica, 2006.

Llamas Martínez, Enrique. "El Apothegmatum opus de Erasmo en una lectura salmantina, 1533-1550”. En El erasmismo en España, editado por Revuelta Sañudo, Manuel - Morón Arroyo, Ciriaco. Santander: Sociedad Menéndez Pelayo, 1986, 219-234.

Manrique Figueroa, César. "From Antwerp to Veracruz. Looking for books from the Southern Netherlands in Mexican colonial libraries". De gulden passer, vol. 87 (2009), 93-109.

Marcocci, Giuseppe - Paiva, José Pedro. História da Inquisição portuguesa, 1536-1821. Lisboa: A Esfera dos Livros, 2013.

Marini, Marco. גי ען / HORTVS EDEN. / GRAMMATICA / LINGVAE SANCTAE [...] Secunda Aeditio [...]. VENETIIS: Ex Officina Ioannis Degarae, 1585. Ejemplar consultado (en línea): Múnich, Bayerische Staatsbibliothek, L.as. 233.

Molekamp, Femke. "Using a collection to discover reading practices: The British Library Geneva Bibles and a history of their early modern readers". Electronic British Library Journal, (2006), 1-13.

Molina, Alonso de. I Aqui comienca [sic] vn vocabula=/rio enla lengua Castellana y Mexicana. Imprimio se e[n] la muy gra[n]de \& insigne y / muy leal ciudad de Mexico: en casa de Iua[n] pablos, 1555. Ejemplar consultado (en línea): "Primeros libros de las Américas", Madrid, Universidad Complutense, Biblioteca Histórica Marqués de Valdecilla, Fondo Francisco Guerra, BH FG 2376.

- VOCABULARIO / EN LENGVA CASTELLANA Y MEXICANA [...]. EN MEXICO: En Casa de Antonio de Spinosa, 1571. Ejemplar consultado (en línea): "Primeros libros de las Américas”, Madrid, Universidad Complutense, Biblioteca Histórica Marqués de Valdecilla, Fondo Francisco Guerra, BH FG 2339.

Murillo Gallegos, Verónica. Cultura, lenguaje y evangelización; Nueva España, siglo XVI. México, D.F.: Porrúa, 2012.

Neurath, Johannes. "Fiestas agrícolas y fiestas católicas-solares en el Gran Nayar". En Historia y vida ceremonial en las comunidades mesoamericanas: los ritos agrícolas, editado por Broda, Johanna - Good Eshelman, Catharine. México, D.F.: Instituto Nacional de Antropología e Historia, Universidad Nacional Autónoma de México, Instituto de Investigaciones Históricas, 2004, 105-125. 
Oberman, Heiko A. "Discovery of Hebrew and discrimination against the Jews: The Veritas Hebraica as double-edged sword in Renaissance and Reformation". En Germania Illustrata: Essays on early modern Germany presented to Gerald Strauss, vol.18, editado por Fix, Andrew C. - Karant-Nunn - Susan C. Kirksville: Truman State University Press, 1992, 19-34.

Offenberg, Adriaan K. "A mid-seventeenth-century manuscript of the (unpublished) Hebrew grammars of Menasseh ben Israel and Isaac Aboab da Fonseca recovered". Zutot, vol. 3 (2003), 98-107.

Ogerio, Paolo Maria. GRAECA ET LATINA LINGUA / HEBRAIZANTES / SEU / DE GRAECAE ET LATINAE LINGUAE / CUM HEBRAICA AFFINITATE / LIBELLUS, / Cui accedit brevis Tractatus de linguae Italicae Hebraismis. VENETIIS [=Venezia]: TYPIS SEBASTIANI COLETI, 1764. Ejemplar consultado: Madrid, Universidad Complutense, Biblioteca Histórica Marqués de Valdecilla, BH FLL 27061.

Olivar, Alejandro. Los sermones de San Pedro Crisólogo: estudio crítico. Barcelona: Abadía de Montserrat, 1962.

Orfali Levi, Moisés. “El Talmud y la Cábala en la 'Epístola a los judíos de Roma' de Alfonso de Zamora". En III Simposio Bíblico Español, editado por Collado Bertomeu, Vicente Vilar Hueso, Vicente. Córdoba: Fundación Bíblica Española, 1985, 671-681.

Osorio Romerio, Ignacio. "El helenismo en México. De Trento a los `filólogos sensualistas'”. Nova Tellus, vol. 4 (1986), 63-117.

— "El helenismo en México: de Trento a los `filólogos sensualistas'”. En Conquistar el eco: la paradoja de la conciencia criolla. México: Universidad Nacional Autónoma de México, 1989, 73-133.

Pagnini, Sante. אוצר לשון הקודש / HOC EST, / THESAVRVS LINGVAE SAN/CTAE. / SIC ENIM INSCRIBERE / placuit Lexicon hoc Hebraicum: quòd quem / admodum ex thesauro pretiosissima quaeque / depromere in procliui est, ita ex hoc uno, non / solum uocularum significata, sed [et] ab/strusiores quosque sacrae scripturae / sensus, è uarijs Rabinorum / commentarijs sele/ctos, hauri/re liceat. Lugduni: SEB[astiano] uerò GRYPHIO excudente, 1529. Ejemplar consultado: Madrid, Universidad Complutense, Biblioteca Histórica Marqués de Valdecilla, BH DER 769.

Pagnini, Sante. Hebraicarum institutionum Libri IIII, / [...] Ex R[abi] Dauid Kim-/hi priore parte מכלול, quam תלק הדקדוק inscripsit, / ferè transcripti. Lutetiae Parisiorum: Ex officina Roberti Stephani typographii Regis, 1549. Ejemplar consultado: Madrid, Universidad Complutense, Biblioteca Histórica Marqués de Valdecilla, BH DER 1490.

Pfeiffer, Robert H. "The teaching of Hebrew in colonial America". The Jewish Quarterly Review, vol. 45 (1955), 363-373. DOI: 10.2307/1452938

Prado Plumed, Jesús de. "Gramáticas hebreas y arameas europeas en el México colonial a través de una lista de libros del Archivo General de Indias". En Conhecimento, cultura e circulação de ideias na América Colonial Luso-hispánica, editado por Alvim, Márcia Helena. Santo André - Belo Horizonte: Universidade Federal do ABC, Fino Traço, 2014, 119-138.

Reinhardt, Klaus. Bibelkommentare spanischer Autoren: (1500-1700), vol. I: Autoren A-LL. Madrid: Consejo Superior de Investigaciones Científicas, 1990.

Ricius, Paulus. PORTAE LVCIS / Hec est porta Tetragra[m]maton iusti intrabu[n]t p[er] eam [...]. Augustae Vindelicoru[m]: Excusa in officina Milleriana, 1516. Ejemplar consultado (en línea): Viena, Österreichische Nationalbibliothek, Sammlung von Handschriften und alten Drucken, 74.T.89.

Robin, Diana. "Intellectual women in early modern Europe". En The Ashgate research companion to women and gender in early modern Europe, editado por Poska, Allyson M. Couchman, Jane - McIver, Katherine A. Abingdon: Ashgate, 2016, 381-406. 
Romero Castelló, Elena. El libro del buen retajar. Textos judeoespañoles de circuncisión. Madrid: Consejo Superior de Investigaciones Científicas, 1998.

Rothschild, Jean-Pierre. "Quelles notions le 'grand public' des lettrés chrétiens dans la France du xvie siècle eut-il de l'hébreu? Enquête parmi les inventaires de bibliothèques". En L'hébreu au temps de la Renaissance, editado por Zinguer, Ilana. Leiden: Brill, 1992, 172-196.

Ruderman, David B. Early modern Jewry: a new cultural history. Princeton: Princeton University Press, 2010.

Saraiva, António José. The Marrano factory. The Portuguese Inquisition and its New Christians, 1536-1765. Leiden: Brill, 2001.

Secret, François. "Pedro Ciruelo: critique de la Kabbale et de son usage par les Chrétiens". Sefarad, vol. 19 (1959), 48-77.

Sherman, William H. Used books: Marking readers in Renaissance England. Philadelphia: University of Pennsylvania Press, 2009.

Szpiech, Ryan. Conversion and narrative: reading and religious authority in medieval polemic. Philadelphia: University of Pennsylvania Press, 2013.

Temkin, Samuel. Luis de Carvajal de la Cueva. Los principios del Nuevo Reino de León. Monterrey: Universidad Autónoma de Nuevo León, Ediciones de Laurel, 2017.

Toro, Alfonso. La familia Carvajal, vol. 2. México, D.F.: Patria, 1944.

Vega Ramos, María José. "Lecturas criptojudías en los siglos áureos: el Ramillete de flores". Studia Aurea. Revista de Literatura Española y Teoría Literaria del Renacimiento y Siglo de Oro, vol. 4 (2010), 37-51.

Vizán, Blanca. "Lecturas criptojudías y la Introducción al símbolo de la fe de fray Luis de Granada". En Las razones del censor. Contro ideológico y censura de libros en la primera Edad Moderna, editado por Esteve, Cesc - Luna, Cristina. Cerdanyola del Vallès: Universitat Autònoma de Barcelona-Servei de Publicacions, 2013, 195-216.

Weijers, Olga. In search of the truth. A history of disputation techniques from Antiquity to early modern times. Turhnout: Brepols, 2013.

Weil, Gérard Emmanuel. Élie Lévita humaniste et massorète (1469-1549). Leiden: Brill, 1963.

Wood, Stephanie - Sullivan, John. Nahuatl Dictionary/Diccionario del Náhuatl/Nahuatlahtolxitlauhquetl. Wired Humanities Project, 2007. Disponible en http://whp.uoregon. edu/dictionaries/nahuatl/.

Yerushalmi, Yosef Hayim. De la corte española al gueto italiano: marranismo y judaismo en la España del XVII. El caso Isaac Cardoso. Madrid: Turner, 1989.

Yhmoff Cabrera, Jesús. Catálogo de obras manuscritas en latín de la Biblioteca Nacional de México, vol. 4. México: Instituto de Investigaciones Bibliográficas, Universidad Nacional Autónoma de México, 1975.

Zapata y Mendoza, Juan Buenaventura. Historia cronológica de la noble ciudad de Tlaxcala. Tlaxcala - México D.F.: Universidad Autónoma de Tlaxcala, Secretaría de Extensión Universitaria y Difusión Cultural, Centro de Investigaciones y Estudios Superiores en Antropología Social, 1995. 